Efeitos da suplementação de selênio sobre a defesa antioxidante na Doença Renal

$$
\text { Crônica }
$$

Effects of selenium supplementation on antioxidant defense in Chronic Kidney Disease Efectos de la suplementación de selenio en la defensa antioxidante en la Enfermedad

\title{
Renal Crónica
}

Recebido: 26/03/2020 | Revisado: 28/03/2020 | Aceito: 03/04/2020 | Publicado: 05/04/2020

\section{Gabriela Cabral Vieira Freitas}

ORCID: https://orcid.org/0000-0002-0081-3859

Universidade Federal do Piauí, Brasil

E-mail: g-cabral@gmail.com

Rita de Cássia Almondes Santana Lemos ORCID: https://orcid.org/0000-0003-1332-1615

Universidade Federal do Piauí, Brasil

E-mail: ritagalis@outlook.com

Amanda Caroline Bandeira França ORCID: https://orcid.org/0000-0002-8564-2058

Universidade Federal do Piauí, Brasil E-mail: amandacaroline18.ac@gmail.com

Laís Cristina Chaves dos Santos

ORCID: https://orcid.org/0000-0002-6396-6238

Universidade Federal do Piauí, Brasil

E-mail: laiscristina8298@gmail.com

Silvia Maria Leite Matos Leão

ORCID: https://orcid.org/0000-0002-1522-108X

Universidade Federal do Piauí, Brasil

E-mail: edilton110@gmail.com

Thaís Rodrigues Nogueira

ORCID: https://orcid.org/0000-0002-2401-033X

Universidade Federal do Piauí, Brasil

E-mail: thaisnogueiranutri@gmail.com 


\section{Resumo}

Introdução: A doença renal crônica é caracterizada pela presença de processos inflamatórios que contribuem para alterações homeostáticas, fisiológicas e funcionais. Essas condições decorrem sobretudo da diminuição da capacidade antioxidante, seja pela deficiência bastante comum de selênio, ou sua perda por processos dialíticos, o que sugere que a suplementação desse mineral pode ser benéfica para esses pacientes. Objetivo: Investigar na literatura os efeitos da suplementação de selênio sobre a atividade antioxidante em pacientes renais crônicos. Métodos: Trata-se de uma revisão integrativa da literatura, realizada por meio de pesquisa de artigos originais, em português, inglês e espanhol, indexados nas bases de dados Pubmed e Lilacs. Resultados: Dos 108 artigos, 5.5\% (n=6) foram incluídos nesta revisão, para leitura integral do texto. Observou-se que 50\% (n=3) dos estudos demonstraram que a suplementação de selênio aumentou a atividade a enzima GSH-Px. Outra metade (50\%, n=3) dos artigos, observou que uma maior concentração de Se no plasma dos pacientes com idade entre 12 e 80 anos, reduziu os níveis séricos de MDA. E apenas 16,6\% (n=1) apontou para um aumento expressivo da atividade de células NK. Conclusão: A suplementação de Se mostrouse eficaz para a melhora da defesa antioxidante de pacientes renais crônicos.

Palavras-chave: Inflamação; Doença renal; Selênio; Suplemento nutricional.

\section{Abstract}

Introduction: Chronic kidney disease is characterized by the presence of inflammatory processes that contribute to homeostatic, physiological and functional changes. These conditions are mainly due to the decrease in antioxidant capacity, either due to the very common deficiency of selenium, or its loss through dialysis processes, which suggests that supplementation of this mineral may be beneficial for these patients. Objective: To investigate in the literature the effects of selenium supplementation on antioxidant activity in chronic renal patients. Methods: This is an integrative literature review, carried out by searching for original articles, in Portuguese, English and Spanish, indexed in the Pubmed and Lilacs databases. Results: Of the 108 articles, 5.5\% $(n=6)$ were included in this review, for full reading of the text. It was observed that $50 \%(n=3)$ of the studies demonstrated that selenium supplementation increased the activity of the enzyme GSH-Px. Another half (50\%, $\mathrm{n}=3$ ) of the articles, observed that a higher concentration of Se in the plasma of patients aged 12 to 80 years, reduced serum MDA levels. And only $16.6 \%(n=1)$ pointed to a significant increase in the activity of NK cells. Conclusion: Se supplementation was shown to be effective in improving the antioxidant defense of chronic renal patients. 
Keywords: Inflammation; Kidney disease; Selenium; Nutritional supplement.

\section{Resumen}

Introducción: La enfermedad renal crónica se caracteriza por la presencia de procesos inflamatorios que contribuyen a los cambios homeostáticos, fisiológicos y funcionales. Estas condiciones resultan principalmente de la disminución de la capacidad antioxidante, ya sea debido a la deficiencia muy común de selenio, o su pérdida a través de procesos de diálisis, lo que sugiere que la suplementación de este mineral puede ser beneficiosa para estos pacientes. Objetivo: Investigar en la literatura los efectos de la suplementación con selenio sobre la actividad antioxidante en pacientes renales crónicos. Métodos: Esta es una revisión integral de la literatura, realizada mediante la búsqueda de artículos originales, en portugués, inglés y español, indexados en las bases de datos Pubmed y Lilacs. Resultados: De los 108 artículos, el 5.5\% ( $n=6)$ se incluyeron en esta revisión, para la lectura completa del texto. Se observó que el $50 \%(\mathrm{n}=3)$ de los estudios demostró que la suplementación con selenio aumentó la actividad de la enzima GSH-Px. Otra mitad (50\%, n=3) de los artículos, observó que una mayor concentración de Se en el plasma de pacientes de 12 a 80 años, redujo los niveles séricos de MDA. Y solo el 16.6\% (n=1) señaló un aumento significativo en la actividad de las células NK. Conclusión: Se demostró que la suplementación con Se es efectiva para mejorar la defensa antioxidante de pacientes renales crónicos.

Palabras clave: Inflamación; Enfermedad renal; Selenio; Suplemento nutricional.

\section{Introdução}

A Doença Renal Crônica (DRC) é considerada um dos maiores problemas de saúde pública da atualidade em todo o mundo (Cao \& Singh, 2020) sendo representativa para os investimentos financeiros na saúde, totalizando gastos superiores a 1,4 bilhões de reais/ano com tratamento de diálise e transplante renal no Brasil (Alcalde \& Kirsztajn, 2018; Junior, et al., 2019).

Nos Estados Unidos, estima-se que 30 milhões de pessoas foram diagnosticadas com IRC (CDCP, 2017). Já no Brasil, cerca de 12 milhões apresentaram algum grau de insuficiência renal e calcula-se que a incidência de IRC possa aumentar em torno de $8 \%$ ao ano, listando como opções efetivas de tratamento para esses casos: diálise peritoneal, hemodiálise e transplante renal (Kdigo, 2012; SBN, 2013). 
Segundo dados da Sociedade Brasileira de Nefrologia (2017) o número total de pacientes em diálise crônica no Brasil, em $1^{\circ}$ de julho de 2017, foi estimado em 126.583. Esse número representa o aumento anual de 3.758 pacientes (3\%), que configura-se como alarmante, quando comparado a três períodos de 5 anos (2002 a 2017), nos quais o aumento médio anual entre 2002 a 2007, 2007 a 2012 e 2012 a 2017, foi respectivamente, 4.960 $(\sim 51 \%), 4.796(32,6 \%)$ e $5.799(29,7 \%)$.

Dentre os desafios no manejo da DRC, citam-se o seu curso, geralmente silencioso nos estágios iniciais da doença, e a dificuldade do diagnóstico precoce, que possivelmente justificam o aumento anual do quantitativo de adoecidos. Somado a isso, outro aspecto relevante é a complexidade das alterações decorrentes da diminuição progressiva da taxa de filtração glomerular (TFG) que determina complicações, propicia comorbidades, aumenta a mortalidade precoce e a falência funcional renal (Horta \& Lopes, 2017).

Como consequência das complicações da doença, é frequente a ocorrência de processos inflamatórios, distúrbios do metabolismo ósseo e mineral, anemia, alterações na fisiologia celular, entre outros, que individual ou conjuntamente, corroboram para o aumento da vulnerabilidade do enfermo (Greffin, et al., 2017).

Acredita-se que os pacientes com DRC apresentam um estado infamatório característico principalmente em decorrência de disfunções patofisiológicas, perdas urinárias e pelo processo dialítico aumentado, e diminuição da capacidade antioxidante (Atakan, 2013). No entanto, além disso, estudos demonstram que quantidades insuficientes de nutrientes protetores, contribuem potencialmente para piora do quadro (Bromann, et al., 2017; Taraz, et al., 2015).

Já existem evidências que comprovam a eficiência da defesa antioxidante estimulada pela incorporação de nutrientes funcionalmente anti-inflamatórios (Bolignano, et al., 2017), a exemplo do selênio, que por meio da enzima glutationa peroxidase (GPx), combate a formação de espécies reativas de oxigênio (EROs) e outros produtos oxidativos (Cai, et al., 2019). Em paralelo, não somente a inserção, como também a suplementação desse mineral tem apontado para respostas positivas ao tratamento, e melhora do prognóstico de dialíticos (Bahmani, et al., 2016; Broman, et al., 2017; Omrani, et al., 2016; Sada, et al., 2016).

Com base nisso, esse estudo tem como objetivo investigar na literatura científica o conhecimento atual sobre os efeitos da suplementação de selênio sobre a defesa antioxidante de pacientes renais crônicos. 


\section{Metodologia}

Trata-se de uma revisão integrativa da literatura realizada nos meses de agosto a dezembro de 2019. Utilizou-se a estratégia PICO (Patient or Problem, Intervention, Control or Comparasion, Outcomes) (Santos, et al.,2007) para a elaboração da pergunta norteadora da busca: "Quais os efeitos da suplementação de selênio sobre a capacidade antioxidante em pacientes renais crônicos?

Foram realizadas consultas na base de dados LILACS (Literatura Latino-Americana e do Caribe em Ciências da Saúde) e PubMed (National Library of Medicine, Bethesda, MD), selecionando artigos publicados em inglês, português e espanhol, entre os anos de 2004 a 2019 e que abordassem os efeitos da suplementação de selênio sobre a capacidade antioxidante em pacientes nefropatas crônicos.

Os termos empregados para a busca foram identificados nos Descritores em Ciências da Saúde (DeCS), e selecionadas as seguintes palavras-chave e seus correspondentes em inglês: doença renal crônica (chronic kidney disease), hemodiálise (hemodialysis), estresse oxidativo (oxidative stress), antioxidantes (antioxidants), selênio (selenium).

Foram definidos como critérios de elegibilidade: Estudos de coorte, do tipo casocontrole e transversal, realizados apenas em humanos, publicados em português, inglês e espanhol e disponíveis na íntegra sem distinção de sexo, raça ou etnia. Como inelegíveis: Estudos de revisão, duplicatas, dissertações, teses, editoriais, ensaios clínicos, experimentais em animais, bem como, estudos publicados nos idiomas alemão, holandês, italiano, coreano, outros e/ou indisponíveis na íntegra.

A seleção dos estudos ocorreu em três etapas: Inicialmente, por meio da análise dos títulos dos artigos, o examinador avaliou aqueles identificados pelas combinações dos descritores nas bases de dados propostas. Em seguida, após seleção pelos títulos relevantes, foi realizada a leitura dos resumos, e após a triagem inicial, os textos foram lidos na íntegra.

Os aspectos avaliados foram: ano de publicação, idioma, desenho e duração do estudo, tamanho da amostra analisada, perdas, objetivo do estudo, intervenção e principais resultados. Para facilitar a análise e discussão, os dados foram organizados no quadro pertencente aos resultados. A Figura 1 abaixo apresenta o fluxograma que detalha o processo de seleção dos artigos que foram incluídos no corpus de análise da revisão. 
Research, Society and Development, v. 9, n. 5, e189953247, 2020

(CC BY 4.0) | ISSN 2525-3409 | DOI: http://dx.doi.org/10.33448/rsd-v9i5.3247

Figura 1. Fluxograma do processo de seleção dos artigos primários. Teresina, 2019.

LVANTAMENTO

BIBLIOGRÁFICO
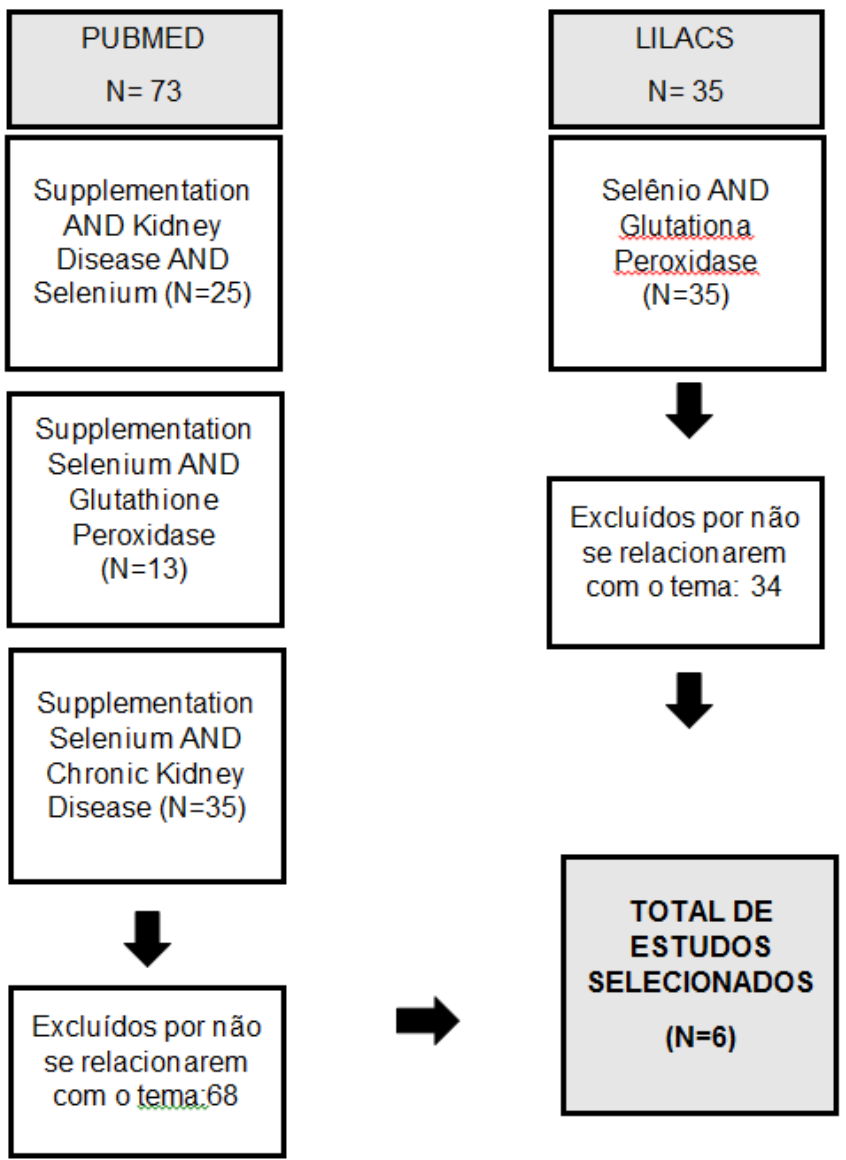

FONTE: Dados da Pesquisa, 2019.

A figura acima identifica o quantitativo obtido a partir da combinação dos descritores definidos para pesquisa nas referidas bases de dados. Observa-se que ao final foram excluídos 68 estudos recuperados no PubMed, e 34 no Lilacs, totalizando apenas 6 artigos que corresponderam aos critérios e a proposta de análise crítica do tema. 


\section{Resultados}

Dos 108 artigos selecionados na busca inicial, apenas 6 foram selecionados para leitura e fichamento. Os artigos selecionados referem-se a publicações nacionais e internacionais, publicados em português e inglês. O período de publicação foi compreendido entre 2004 e 2019 . Desse modo, a amostra final desse estudo foi constituída por 6 artigos científicos, selecionados pelos critérios de inclusão previamente estabelecidos e abordam os efeitos da suplementação de selênio em pacientes renais crônicos.

Quadro 1. Estudos incluídos que abordam a suplementação de selênio em pacientes renais crônicos. Teresina, 2019.

\begin{tabular}{|c|c|c|c|c|c|}
\hline Autor/Ano & Objetivo & Tipo de Estudo & $\begin{array}{c}\text { Caracterização da } \\
\text { Amostra } \\
\end{array}$ & $\begin{array}{l}\text { Dose/tempo de } \\
\text { suplementação }\end{array}$ & $\begin{array}{c}\text { Principais } \\
\text { resultados/conclusões }\end{array}$ \\
\hline $\begin{array}{l}\text { Zachara, et al., } \\
2004\end{array}$ & $\begin{array}{l}\text { Aavaliar o efeito da } \\
\text { suplementação de Se } \\
\text { sobre a atividade } \\
\text { plasmática de GSH-Px } \\
\text { em pacientes com IRC } \\
\text { em seus diferentes } \\
\text { estágios. }\end{array}$ & Caso-controle. & $\begin{array}{l}\mathrm{N}=53 \text { pacientes, sendo } \\
21 \text { homens e } 32 \\
\text { mulheres com idade } \\
\text { entre } 25 \text { e } 81 \text { anos }\end{array}$ & $\begin{array}{l}100 \mu \mathrm{g} \text { Se durante } 3 \\
\text { meses. }\end{array}$ & $\begin{array}{l}\text { Após suplementação, a } \\
\text { concentração de Se e a } \\
\text { atividade da GSH-Px } \\
\text { aumentaram } \\
\text { significativamente. }\end{array}$ \\
\hline $\begin{array}{l}\text { Zachara, et al., } \\
2009\end{array}$ & $\begin{array}{l}\text { Avaliar o efeito da } \\
\text { suplementação de de } \\
\text { selênio sobre atividade } \\
\text { plasmática da glutationa } \\
\text { peroxidase em } \\
\text { pacientes com IRC. }\end{array}$ & $\begin{array}{l}\text { Duplo-cego } \\
\text { randomizado, } \\
\text { placebo e controle. }\end{array}$ & $\begin{array}{l}\mathrm{N}=30 \text { pacientes e } \mathrm{N} \\
\text { placebo= } 28 \text { pacientes, } \\
\text { idade de } 12 \text { anos a } 61 \\
\text { anos de ambos os sexos }\end{array}$ & $\begin{array}{l}200 \mu \mathrm{g} \text { de Se/dia por } 3 \\
\text { meses }\end{array}$ & $\begin{array}{l}\text { A suplementação de Se em } \\
\text { pacientes com DRC em } \\
\text { HD não teve efeito sobre o } \\
\text { nível da enzima GSH-Px. }\end{array}$ \\
\hline Pinto, 2009 & $\begin{array}{l}\text { Avaliar o efeito da } \\
\text { suplementação de Se } \\
\text { por meio da castanha do } \\
\text { Brasil no estado } \\
\text { nutricional relativo ao } \\
\text { Se em pacientes em } \\
\text { hemodiálise. }\end{array}$ & Longitudinal. & $\begin{array}{l}\mathrm{N}=81 \text { pacientes, sendo } \\
55 \text { homens e } 26 \\
\text { mulheres com idade } \\
\text { entre } 20 \text { a } 76 \text { anos. }\end{array}$ & $\begin{array}{l}\text { Suplementou-se uma } \\
\text { castanha-do- Brasil por } \\
\text { dia }(4,5 \mathrm{~g}) \text { que continha } \\
\text { cerca de } 58,1 \mu \mathrm{g} \text { de } \mathrm{Se} / \mathrm{g} \\
\text { durante três meses }\end{array}$ & $\begin{array}{l}\text { A suplementação com } \\
\text { castanha do Brasil foi } \\
\text { eficiente no aumento dos } \\
\text { níveis de Se plasmático e } \\
\text { eritrocitário, e sobre a } \\
\text { atividade eritrocitária da } \\
\text { GSH-Px. }\end{array}$ \\
\hline
\end{tabular}


Research, Society and Development, v. 9, n. 5, e189953247, 2020

(CC BY 4.0) | ISSN 2525-3409 | DOI: http://dx.doi.org/10.33448/rsd-v9i5.3247

\begin{tabular}{|c|c|c|c|c|c|}
\hline $\begin{array}{l}\text { Salehi, et al., } \\
2013\end{array}$ & 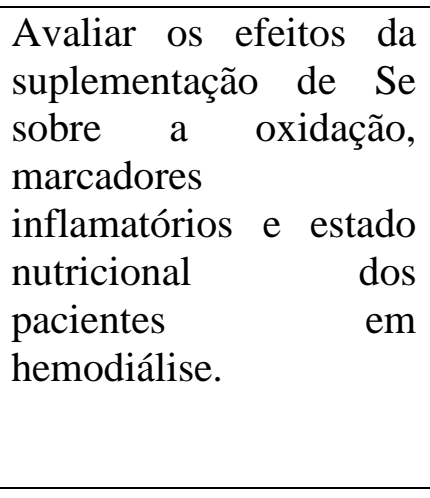 & $\begin{array}{l}\text { Randomizado, } \\
\text { duplo-cego, } \\
\text { controle e placebo. }\end{array}$ & $\begin{array}{l}\mathrm{N}=80 \text { pacientes, idade } \\
18 \text { a } 80 \text { anos de ambos } \\
\text { os sexos. }\end{array}$ & $\begin{array}{l}\text { Uma cápsula de selênio } \\
\text { na forma de levedura de } \\
\text { selênio }(200 \quad \mu \mathrm{g}) \\
\text { diariamente por doze } \\
\text { semanas. }\end{array}$ & $\begin{array}{lr}\text { O grupo } & \text { suplementado } \\
\text { apresentou } & \text { redução } \\
\text { significativa dos níveis } \\
\text { séricos de MDA, como } \\
\text { também, reduziu-se o } \\
\text { aumento da liberação de } \\
\text { IL-6 no grupo } \\
\text { suplementado, no grupo } \\
\text { suplementadoarados com o } \\
\text { grupo placebo. }\end{array}$ \\
\hline $\begin{array}{l}\text { Sedighi, et al., } \\
2014\end{array}$ & $\begin{array}{l}\text { Avaliar o efeito } \\
\text { suplementação de } \\
\text { sobre Se } \\
\text { concentração } \\
\text { plasmática e atividade } \\
\text { da GSH-Pxs em } \\
\text { pacientes em diferentes } \\
\text { estágios da DRC. }\end{array}$ & Randomizado. & $\begin{array}{l}\mathrm{N}=45 \text { pacientes, sendo } \\
24 \text { homens e } 21 \\
\text { mulheres com idade } \\
\text { entre } 20 \text { a } 65 \text { anos. }\end{array}$ & $\begin{array}{l}\text { Os pacientes foram } \\
\text { suplementados com } 200 \\
\mu \mathrm{g} \text { de Se, durante três } \\
\text { meses. }\end{array}$ & $\begin{array}{l}\text { A concentração plasmática } \\
\text { de Se e a atividade de } \\
\text { GSH-Pxs de glóbulos } \\
\text { vermelhos aumentaram } \\
\text { significativamente nos três } \\
\text { grupos de pacientes com } \\
\text { DRC. }\end{array}$ \\
\hline $\begin{array}{l}\text { Sadah, et al., } \\
2016\end{array}$ & $\begin{array}{l}\text { Verificar o efeito da } \\
\text { suplementação de Se } \\
\text { combinada a outro } \\
\text { mineral, sobre a } \\
\text { atividade das células } \\
\text { natural Killer, e na } \\
\text { relação com a função } \\
\text { cardíaca de pacientes } \\
\text { em hemodiálise. }\end{array}$ & Longitudinal. & $\begin{array}{l}\mathrm{N}=18 \text { pacientes, sendo } \\
10 \text { homens e } 8 \text { mulheres } \\
\text { com idade de } 73 \pm 13 \\
\text { anos. }\end{array}$ & $\begin{array}{l}125 \mathrm{~mL} \text { de bebida rica } \\
\text { em vitaminas e minerais } \\
\text { (V CRESC@) com } 12 \\
\text { tipos de vitamina e } 10 \\
\text { tipos mineral, incluindo } \\
50 \mu \mathrm{g} \text { de Se e } 12 \mathrm{mg} \text { de } \\
\mathrm{Zn} \text {, uma vez por dia, por } \\
\text { três meses. }\end{array}$ & $\begin{array}{l}\text { A fórmula administrada } \\
\text { diminuiu } \\
\text { significativamente } \\
\text { dimensão do VE desses } \\
\text { pacientes, após } 3 \text { meses de } \\
\text { suplementação de Se } \\
\text { combinada com outro } \\
\text { mineral. }\end{array}$ \\
\hline
\end{tabular}

GSH-Px: Glutationa Peroxidase; IRC:Insuficiência Renal Crônica; DRC: Doença Renal Crônica HD:Hemodiálise; MDA: Malondialdeído VE: Ventrículo esquerdo; NK:

Ntural Killer; IL-6: Interleucina 6; Zn: Zinco; Se: Selênio. FONTE: Dados da Pesquisa. Teresina, 2019 


\section{Discussão}

A literatura científica tem demonstrado que várias categorias de antioxidantes da dieta, dentre eles o selênio, podem ser efetivos em suprimir a ativação de vias pró-inflamatórias, por meio da quelação das moléculas de radicais livres. Esses nutrientes essenciais bloqueiam a ativação do fator de transcrição Nuclear Kappa-beta $(\mathrm{NF}-\kappa \beta)$, um regulador sensível a oxidantes que modula a produção de mediadores inflamatórios e de moléculas de adesão (CAM). Esse raciocínio sugere que em condições de baixa ingestão de antioxidantes, há maior probabilidade da ativação do NF- $\kappa \beta$ (Walston, et al., 2006). O selênio, por sua vez, pode exercer um papel fundamental em minimizar o desenvolvimento dos eventos inflamatórios, por reduzir a atividade pró-oxidante em detrimento do sistema antioxidante, como os estudos abaixo confirmam.

Sada, et al. (2016) constataram que após suplementação com bebida rica em minerais e vitaminas, os pacientes com DRC e em hemodiálise, apresentaram aumento significativo nos níveis séricos de Se e Zn, após 3 meses de intervenção. Além disso, a atividade das células NK (Natural Killer) foi beneficiada, o que pode ser comprovado pela atividade citolítica sobre células infectadas e infecções graves. Apesar dos achados, o tamanho amostral reduzido, revela a limitação no detalhamento do papel do Se para esse grupo adoecido, bem como, sua atividade sobre células NK.

Segundo a literatura, a produção de espécies reativas de oxigênio aumenta progressivamente com o avanço da DRC, o que evidencia que o grau de estresse oxidativo pode também sofrer influência de alterações nos níveis plasmáticos de oligoelementos, especialmente o Se (Guo, 2011; Ko, 2005). Essas correlações são atribuídas sobretudo a função biológica, amplamente discutida e mais importante do selênio, de constituir a enzima antioxidante glutationa peroxidase (GPx) (Silva, et al., 2020). Logo, concentrações baixas de selênio contribuem para a ocorrência de doenças crônicas e/ou complicações, a exemplo da aterosclerose e hiperhomocisteinemia, como visto no estudo de González (2004).

Sabendo que os processos de peroxidação lipídica são iniciados pela reação de um radical livre com um ácido graxo insaturado, e propagados por radicais peroxilas, verifica-se que essa dinâmica estimula cascatas de eventos bioquímicos e de formação de produtos, como malondialdeído (MDA), que podem avaliar o estresse oxidativo, e ser útil para correlação com o estado nutricional do selênio (Cotinguiba, et al., 2013). No estudo desenvolvido por Salehi e colaboradores (2012), por exemplo, observou-se que uma diminuição significativa nos níveis séricos de MDA no grupo suplementado com uma cápsula de selênio durante 12 
semanas, se comparado ao grupo placebo. Segundo os autores, esse efeito fundamenta-se na ação do selênio no combate ao estresse oxidativo e a inflamação.

No estudo desenvolvido por Pinto (2009), observou-se um aumento da concentração plasmática e eritrocitária do Se e da atividade da glutationa peroxidase (GSH-Px), em relação a sua atividade antes da suplementação. Sedighi (2014) também mostrou que a suplementação de Se foi eficaz no aumento da atividade celular de GSH-Pxs de indivíduos em diferentes estágios da DRC, logo, a suplementação de Se tem implicações no aumento da sobrevida desses pacientes.

Zachara, et al. (2004), observaram que em pacientes com DRC, as concentrações de Se no sangue total e no plasma mostraram-se baixas, em comparação ao grupo controle saudável. Notou-se que a atividade da GSH-Px, das células sanguíneas permaneceu inalterada, enquanto que a atividade plasmática de GSH-Px foi acentuadamente reduzida. Além disso, em todos os estágios da DRC, a suplementação do mineral implicou em um aumento uniforme na sua concentração nos diferentes componentes sanguíneos.

Em contrapartida, foi observado que pacientes suplementados com Se, tiveram a atividade plasmática de GSH-Px ligeiramente aumentada no estágio inicial da doença, mas inalterada em seu estágio final. Esses dados sugerem que o comprometimento da capacidade funcional de GSH-Px nos pacientes com DRC, está relacionada ao grau do trauma renal, e não diretamente à deficiência de Se, sendo que a medida no plasma da atividade da GSH-Px, pode ser um marcador adicional no diagnóstico do estágio da uremia.

Outro estudo realizado por Zachara, et al. (2009), mostrou que a após 3 meses de suplementação de Se em pacientes em HD, a concentração do elemento plasmático aumentou significativamente, quando comparado ao valor inicial. Porém, mesmo com o aumento da concentração de Se no plasma em resposta a suplementação, os níveis da GSH-Px, que inicialmente encontravam-se baixos, permaneceram sem alterações. Isso pode indicar que no estágio final da DRC os danos nos túbulos renais podem torna-los incapazes de sintetizar esta enzima, muito embora tenha sido suplementado Se.

Por sua vez, o estudo Zachara, et al. (2009) demonstrou que a suplementação de Se em pacientes com DRC em HD não teve efeitos sobre os níveis plasmáticos de GSH-Px, ainda que outros estudos já tenham constatado que a suplementação do mineral pode induzir a síntese da enzima em outros tecidos. 


\section{Conclusão}

Os resultados dos estudos sugerem a existência de forte associação entre a suplementação de selênio e melhora da função antioxidante nos pacientes renais. Essa constatação é possivelmente explicada pelo envolvimento do mineral em vias funcionais essências à fisiologia e combate dos processos oxidativos. Os efeitos positivos do seu uso, produzem ainda melhora do prognóstico da doença, redução do quadro de desnutrição e estado inflamatório.

Apesar disso, ressalta-se a importância de mais investigações que possam elucidar aspectos relacionados a dose e tempo de suplementação ideais, além de outras vias de interação.

\section{Referências}

Alcalde, P.R. \& Kirsztajn, G.M. (2018). Gastos do Sistema Único de Saúde brasileiro com doença renal crônica. Braz. J. Nephrol. (J. Bras. Nefrol.), 40(2),122-129.

Atakan, A., Macunluoglu, B., Kaya, Y., Ari, E., Demir, H., Asicioglu, E., Altunok, E.C. (2013). Decreased serum selenium levels are correlated with diminished coronary flow reserve among hemodialysis patients. Biol Trace Elem Res, 155(3), 333-8

Bahmani, F., Kia, M., Soleimani, A., Mohammadi, A.A., Asemi, Z. (2016). The effects of selenium supplementation on biomarkers of inflammation and oxidative stress in patients with diabetic nephropathy: a randomised, double-blind, placebo-controlled trial. Br J Nutr. 116(7), $1222-1228$.

Bastos, M.G. \& Kirstajn, G.M. (2011). Doença renal crônica: importância do diagnóstico precoce, encaminhamento imediato e abordagem interdisciplinar estruturada para melhora do desfecho em pacientes ainda não submetidos à diálise. J Bras Nefrol, 33(1), 93-108.

Bolignano, D., Cernaro, V., Gembillo, G., Baggetta, R., Buemi, M., D'Arrigo, G. (2017). Antioxidant agents for delaying diabetic kidney disease progression: A systematic review and meta-analysis. PLoS One. 12(6), 1-16. 
Broman, M., Bryland, A., Carlsson, O. (2017). Trace elements in patients on continuous renal replacement therapy. Acta Anaesthesiol Scand. 61(6), 650-659.

Cai, Z., Zhang, J., Li, H. (2019). Selenium, aging and aging-related diseases. Aging Clin Exp Res. 31(8), 1035-1047.

Cao, J. \& Singh, K. (2020). Integrating risk prediction models into chronic kidney disease care. Curr Opin Nephrol Hyperten, 29(2).

Centers for Disease Control and Prevention. National Chronic Kidney Disease Fact Sheet. (2017). Atlanta, GA: US Department of Health and Human Services, Centers for Disease Control and Prevention.

Oliveira, C.M.C., Kubrusly, M., Mota, R.S., Silva, C.A.B., Oliveira, V.N. (2010). Desnutrição na insuficiência renal crônica: qual o melhor método diagnóstico na prática clínica? J Bras Nefrol, 32(1), 57-70.

Cotinguiba, G.G., Silva, J.R.N., Azevedo, R.R.S., Rocha, T.J.M., Santos, A.F. (2013). Método de Avaliação da Defesa Antioxidante: Uma Revisão de Literatura. UNOPAR Cient Ciênc Biol Saúde, 15(3), 231-7.

González, S., Huerta, J.M, Álvarez-Uría, J., Fernández, S., Patterson, A.M, Lasheras, C. (2004). Serum selenium is associated with plasma homocysteine concentrations in elderly humans. J Nutr, 134 (7), 1736-40.

Greffin, S., André, M.B., Matos, J.P.S., Kang, H.C., Jorge, A.J.L., Rosa, M.L.G., Lugon, J.R. (2017). J Bras Nefrol, 39(3), 246-252

Guo, C.H, Wang, C.L, Chen, P.C, Yang, T.C. (2011). Linkage of some trace elements, peripheral blood lymphocytes, inflammation, and oxidative stress in patients undergoing either hemodialysis or peritoneal dialysis. Perit Dial Int, 31(5), 583-91. 
Horta, H.H.L. \& Lopes, M.L. (2017). Complicações decorrentes do tratamento dialítico: contribuição do enfermeiro no cuidado e educação ao paciente. Revista Enfermagem Contemporânea, 6(2), 221-227.

Junior, E.V.S., Costa, E.L., Matos, R.A., Cruz, J.S., Maia, T.F., Nunes, G.A., Boery, R.N.S.O., Boery, E.N. (2019). Epidemiologia da morbimortalidade e custos públicos por insuficiência renal. Rev enferm UFPE on line, 13(3), 647-54.

Ko, W.S., Guo, C.H., Yeh, M.S., Lin, L.Y., Hsu, G.S.W., Chen, P.C., Luo, M.C., Lin, C.Y. (2005). Blood micronutrient, oxidative stress, and viral load in patients with chronic hepatitis C. World J Gastroenterol, 11(30), 4697-4702.

National Kidney Foundation, KDIGO, Kidney Disease Improving Global Outcomes. (2012). Am J Kidney Dis, 3(1). Disponível em: http://kdigo.org/home/glomerulonephritis-gn/.

Obrador, G.T., Mahdavi-Mazdeh, M., Collins, A.J., Global Kidney Disease Prevention Network. et al. (2011). Establishing the Global Kidney Disease Prevention Network (KDPN): a position statement from the National Kidney Foundation. Am J Kidney Dis, 57(3), 361-70.

Pinto, M.B.S. (2009). Efeitos da suplementação com Castanha-do-Brasil (Bertholletia Excelsa H.B.K.) como fonte de selênio para pacientes em hemodiálise. Faculdade de Ciências Farmacêuticas da Universidade de São Paulo.

Sada, H., Kato, A., Sumimoto, R., Ohmori, H., Ohdan, H. (2016). Effects of nutritional supplementation with selenium and zinc on natural killer cell activity in hemodialysis patients: a single-arm study. Int Urol Nephrol. 48(8), 1377-1378.

Salehi, M., Sohrabi, Z., Ekramzadeh, M., Fallahzadeh, M.K., Ayatollahi, M., Geramizadeh, B., Hassanzadeh, J., Sagheb, M.M. (2013). Selenium supplementation improves the nutritional status of hemodialysis patients: a randomized, double-blind, placebocontrolled trial. Nephrol Dial Transplant, 28(3), 716-23. 
Santos, C.M.C.; Pimenta, C.A.M.; Nobre, M.R.C. (2007). A estratégia PICO para a construção da pergunta de pesquisa e busca de evidências. Rev. Latino-Am. Enfermagem. 15(3), 508-511.

Sedighi, O., Zargari, M., Varshi, G. (2014) Effect of Selenium Supplementation on Glutathione Peroxidase Enzyme Activity in Patients With Chronic Kidney Disease: A Randomized Clinical Trial. Nephrourol Mon, 6(3).

Silva, A.G.S., Dantas, L.S.A., Nogueira, T.R., Freitas, B.J.S.A. (2020). Comportamento do Selênio e Atividade da Glutationa Peroxidase Dependente de Selênio na Fibrose Cística. Research, Society and Development, 9(4), 1-15.

Sociedade Brasileira de Nefrologia. Censo 2013 [Internet]. São Paulo: SBN; 2013 [citado 15 Mar 2016]. Disponível em: http://www.sbn.org.br

Stockler-Pinto, M.B., Lobo, J., Moraes, C., Leal, V.O., Farage, N.E., Rocha, A.V., Boaventura, G.T., Cozzolino, S.M., Malm, O., Mafra, D. (2012). Effect of Brasil nut supplementation on plasma levels of selenium in hemodialysis patients: 12 months of followup. J Renal Nutr, 22(4), 434-9.

Sociedade Brasileira de Nefrologia. Censo de diálise. 2017 [internet]. São Paulo;2017. Disponível em: www.censo-sbn.org.br.

Taraz, M., Taraz, S., Dashti-Khavidaki, S. (2015). Association between depression and inflammatory/anti-inflamatory cytokines in chronic kidney disease and end-stage renal disease patients: A review of literature. Hemodial Int, 19(1), 11-22.

Tonelli, M., Wiebe, N., Hemmelgarn, B., Klarenbach, S., Field, C., Manns, B., Thadhani, R., Gill, J., Alberta Kidney Disease Network. (2009). Trace elements in hemodialysis patients: a systematic review and meta-analysis. BMC Med. 7, 25-37.

Walston, J., Xue, Q., Semba, R.B., Ferrucci, L., Cappola, A.R., Ricks, M., Guralnik, J., Fried, L.P. (2006). Serum antioxidants, inflammation, and total mortality in older women. American Journal of Epidemiology, 163(1), 18-26. 
Wiggins, J., \& Patel, S. (2010). Management of chronic kidney disease in older adults. Aging Health, 6(1), 41-51.

Zachara, B.A., Gromadzinska, J., Zbrog, Z., Swiech, R., Wasowicz, W., Twardowska, E., Jablonska, E., Sobala, W. (2009). Selenium supplementation to chronic kidney disease patients on hemodialysis does not induce the synthesis of plasma glutathione peroxidase. Acta Biochim Pol., 56(1), 183-7.

Zachara, B.A., Koterska, D., Manitius, J., Sadowski, L., Dziedzicsko, A., Salak, A., Wasowicz, W. (2004). Selenium Supplementation on Plasma Glutathione Peroxidase Activity in Patients with End-Stage Chronic Renal Failure. Biological Trace Element Research, 97(1), 15-30.

\section{Porcentagem de contribuição de cada autor no manuscrito}

Gabriela Cabral Vieira Freitas - 23\%

Rita de Cássia Almondes Santana Lemos - 23\%

Amanda Caroline Bandeiras França - 10\%

Laís Cristina Chaves dos Santos - 10\%

Silvia Maria Leite Matos Leão - 10\%

Thaís Rodrigues Nogueira - 24\% 